\title{
Cycling hypoxia affects cell invasion and proliferation through direct regulation of claudin1 / claudin7 expression, and indirect regulation of P18 through claudin7 \\ This article has been corrected. Correction in: Oncotarget. 2021; 12:1966-1969.
}

\author{
Hong Liu ${ }^{1}$, Feifei Jiang1, Xinshan Jia², Jing Lan ${ }^{3}$, Hao Guo ${ }^{3}$, Erran Li ${ }^{4}$, Aihui Yan ${ }^{1}$, \\ Yan Wang ${ }^{1}$ \\ ${ }^{1}$ Department of Otolaryngology, The First Affiliated Hospital of China Medical University, Shenyang, Liaoning 110001, China \\ ${ }^{2}$ Department of Pathology, China Medical University, Shenyang, Liaoning 110001, China \\ ${ }^{3}$ Department of Dermatology, China Medical University, Shenyang, Liaoning 110001, China \\ ${ }^{4}$ Institute of Respiratory Disease, The First Affiliated Hospital of China Medical University, Shenyang, Liaoning 110001, China \\ Correspondence to: Yan Wang, email: wangyan@mail.cmu.edu.cn \\ Hong Liv, email: 13889385073@163.com
}

Keywords: claudin 1, claudin7, HIFla, cycling hypoxia, nasopharyngeal carcinoma

Received: February 16, $2016 \quad$ Accepted: December 05, 2016

Published: December 31, 2016

\section{ABSTRACT}

Claudins (CLDNs), the major integral membrane proteins at tight junction, play critical roles in apical cell-to-cell adhesion, maintenance of epithelial polarity, and formation of impermeable barriers between epithelial cells.

We investigated in this study the expression of CLDNs- Claudin1 (CLDN1) and Claudin7 (CLDN7), and their relation to tumor progression in nasopharyngeal cancer (NPC). CLDN7, rather than CLDN1, showed higher expression in both undifferentiated tumor tissue and the poorly differentiated CNE2 cells, compared with differentiated tissue and the highly differentiated CNE1 cells. Furthermore, knockdown of CLDN7 dramatically inhibited the metastasis and invasion of CNE2 cells suggesting that CLDN7 could act as a biomarker for NPC metastasis.

Cycling hypoxia could induce significant changes in CLDN1 and CLDN7 expression in NPC cells. Genetics analysis demonstrated that CLDN1/CLDN7 were not only regulated directly by HIF1a but also affected each other through a feedback mechanism. CLDN7 acted as a bridge to promote HIF1a-induced P18 expression and cell differentiation. Taken together, our results provide evidence that adjusting the oxygenation time and cycles in NPC might be an effective method to prevent / delay the metastasis of poorly differentiated NPC cells.

\section{INTRODUCTION}

Claudins $(C L D N S)$ play an essential role in the function of the tight junction (TJ), and the maintenance of the polarity of epithelial cells. So far, 24 CLDNs subtypes have been identified [1-3]. Previous studies have identified the expression of $C L D N s$ in several cancer types, and demonstrated that even the same $C L D N$ subtype might have different functions in tumorigenesis and metastasis in different cancers. Several papers define the ultrastructural anatomy of the tight junction and suggest that a single tight junction with differences in protein composition and structure in different subdomains [4-5]. Some of the $C L D N s$ also can form strands in other non-epithelial cell or be found outside of TJ [6-8], where their functions are still disputed.

CLDN1 has been predicted to act as a tumor suppressor gene in carcinomas of breast, prostate, colon, and liver [9-15]. However, the high expression of CLDN1 can mediate $\mathrm{TNF} \alpha$-induced gene expression, promote cell invasion and inhibit apoptosis in human gastric adenocarcinoma MKN28 cells, MCF7 breast cancer cells and A549 lung cancer cells [16-18]. In nasopharyngeal carcinoma (NPC) cells, up-regulated CLDN1 expression confers resistance to cell death [19].

A lack of $C L D N 7$ is a strong indicator of regional recurrence in oral and oropharyngeal squamous cell carcinoma [20]. However, in ovarian carcinoma, CLDN7 
is significantly up-regulated and may be functionally involved in ovarian carcinoma metastasis [21]. CLDN7 over expression in the human gastric adenocarcinoma cell line AGS can increases its invasiveness, migration, and proliferation. CLDN7 can form a complex with EpCAM, CD44 variant isoforms, and tetraspanins to promote colorectal cancer progression $[22,23]$. In NPC, CLDN7 overexpression is associated with metastasis and a low survival rate $[24,25]$. Several studies further reported that CLDN7 had polymerization tendency and can be found outside of TJ [26], and that the role of CLDN7 in tumor was associated with their polymerization and localization status inside the cells [26, 27].

Clinical studies have shown that $100 \%$ of primary NPCs and $58 \%$ of cervical nodal metastases of NPCs contain hypoxic regions [28]. HIF $1 \alpha$ protein is over expressed in NPC tissues compared with normal nasopharyngeal tissues, and plays a major role in tumor development, including growth rate, invasiveness, angiogenesis, and metastasis [29]. However, the effect of hypoxia on the expression of CLDNs in NPCs remains unknown.

The present study aimed to evaluate the expression of CLDN1 and CLDN7 under different cell differentiation status, and their relationship to tumor progression in NPCs. The impact of hypoxia on CLDN1 and CLDN7 expression was also evaluated in a hypoxicmodel.

\section{RESULTS}

\section{The $C L D N 1 / C L D N 7$ expression are correlated to the differentiation status of the nasopharyngeal cancer}

The samples were divided into two groups: low $C L D N 1 / C L D N 7$ expression (score of 0 to 2 ) or high $C L D N 1 / C L D N 7$ expression (score of 3 to 9) samples. As shown in Figure 1, CLDN1 expression rate was high at $65.6 \%(25 / 38$, Figure 1C) and 68\% (17/25, Figure 1D) in differentiated and undifferentiated NPC specimens, respectively. $C L D N 7$ expression rate was shown at $42.5 \%$ $(17 / 40$, Figure $1 \mathrm{G})$ and $61.5 \%(16 / 26$, Figure $1 \mathrm{H})$ in the differentiated vs. undifferentiated NPC specimens, respectively. CLDN7 expression was negatively correlated with the differentiation status of the nasopharyngeal squamous cell carcinoma, with a higher expression in undifferentiated NPC samples (Figure 1H).

\section{Correlation between $C L D N 1 / C L D N 7$ expression and nasopharyngeal cancer cell differentiation}

We next used CNE1/CNE2 cells to further confirm the result above. CNE1/CNE2 cells represent welldifferentiated and poorly differentiated NPC cells, respectively. We evaluated the correlation between $C L D N 1 / C L D N 7$ expression and the differentiation status of the cells. The real-time PCR (for primer sequences, see Table 1) and Western blot results showed that there were significantly higher expression of CLDN1/CLDN7 in CNE2 than in CNE1 (Figure 1I).

Combined with the immunohistochemical staining data above, CLDN7 demonstrated that the expression in poorly differentiated carcinoma was significantly higher, suggesting a close association with the differentiation of NPC tissue and cells. Because the poor differentiation of cancer is generally considered to be related to high metastasis and low survival rate, therefore we took the next step to investigate the correlation of CLDN7 expression with the invasion of NPC.

\section{CLDN7 promotes NPC invasion and migration}

CNE2 cells with high CLDN7 expression, indeed demonstrated a greater migration capacity compared to CNE1 cells (Figure 2A), which supports the hypothesis that cells with poor differentiation status have high tendency of migration and invasion. Using small interfering RNA technology (for the si-RNA silencing gene sequences, see Table 2), we knocked down CLDN7 in CNE2 to investigate the correlation between CLDN7 and the cell invasion capacity. The result showed that the cell invasion and migration index was significantly decreased after si-RNA transfection for 24-48 h (Figure 2B \& 2C), suggesting that CLDN7 could enhance the metastasis of NPC.

\section{The different responses of CNE1/CNE2 cells to hypoxia is associated with their differentiation status}

NPC cells were incubated in a hypoxic atmosphere of $0.1 \% \mathrm{O}_{2}, 5 \% \mathrm{CO}_{2}$, and $94 \% \mathrm{~N}_{2}$ at $37^{\circ} \mathrm{C}$ for $8,16,24$ or $48 \mathrm{~h}$. HIF $1 \alpha$ expression was investigated using real-time PCR and Western blotting (Figure 3D). Cell proliferation and viability were then assessed using EdU and MTT assay (Figure 3A, 3B, 3C). The transwell analysis was performed to analyze NPC migration and invasion (Figure 4A, 4B). As a control, the cells were incubated at normoxic conditions of $20 \% \mathrm{O}_{2}, 5 \% \mathrm{CO}_{2}$, and $75 \%$ $\mathrm{N}_{2}$. The results showed that the different reactions of CNE1/CNE2 cells to hypoxia are associated with their differentiation status. CNE2, as a relatively poorly differentiated NPC cell line, was more sensitive to hypoxia than CNE1. The expression levels of HIF1 $\alpha$ mRNA and protein in CNE2 were up-regulated under hypoxic conditions at $24 \mathrm{~h}$ and $48 \mathrm{~h}$, and CNE1 cells exhibited a similar trend in mRNA levels. However, HIF $1 \alpha$ protein levels were slightly reduced at $24 \mathrm{~h}$ and $48 \mathrm{~h}$ in CNE1 cells. Hypoxic conditions inhibited cell proliferation, and enhanced the migration and invasion ability of CNE2 cells; but accelerated cell proliferation and decreased the migration and invasion ability of CNE1 cells (Figure 3). 


\section{Hypoxia altered $C L D N 1 / C L D N 7$ expression in NPCs}

HIF $1 \alpha$ is considered an independent prognostic indicator $[28,29]$ and is closely related to the invasion of NPC. Clinical studies have shown that $100 \%$ of primary NPC tumors and $58 \%$ of cervical nodal NPC metastasis contain hypoxic regions [28]. Under a hypoxic environment, the changes of $C L D N$ proteins, which are important components of the cell membrane, could also potentially affect the NPC development including metastasis.
To investigate the impact of hypoxia in the expression of $C L D N 1 / C L D N 7$ in NPCs, we examined the expression variations of their mRNA and protein levels after cells were exposed to hypoxic conditions for different duration of time. Although the protein expression of $C L D N 1$ significantly decreased in both cells, there was a slight up-regulation in the mRNA levels at $24 \mathrm{~h}$ in CNE1 cells and $8 \mathrm{~h}$ in CNE2 cells. Compared with CNE2 cells, the $C L D N 1 / C L D N 7$ proteins were down-regulated more sharply in CNE1, and with CLDN1 barely detectable from $16 \mathrm{~h}$ post hypoxia exposure (Figure $4 \mathrm{E}$ ).

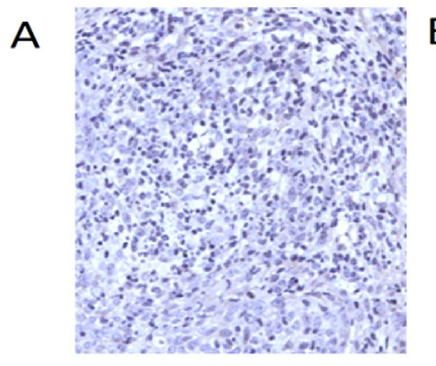

$B$

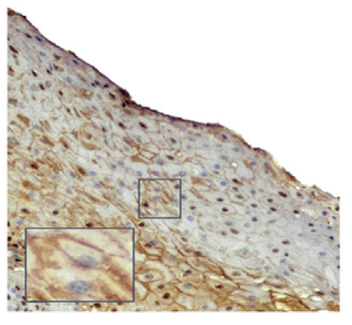

E

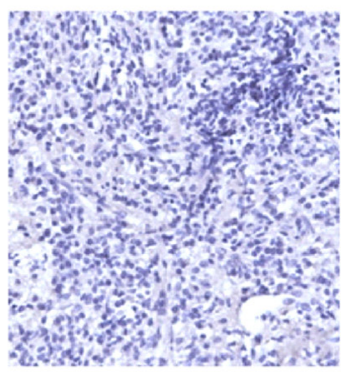

$F$

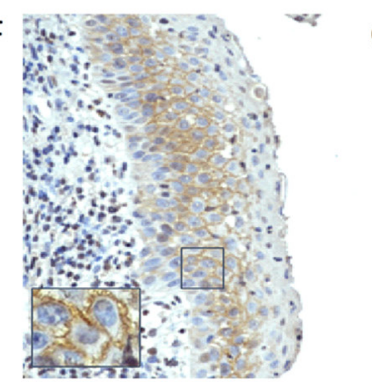

C
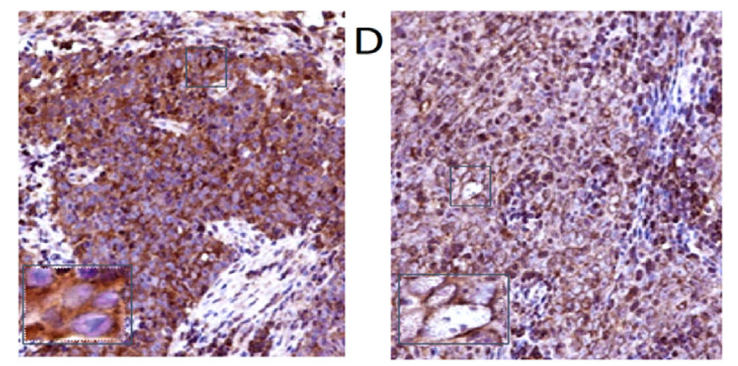

G

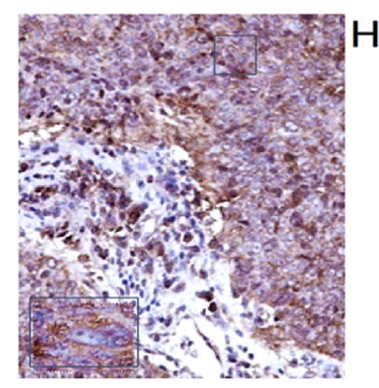

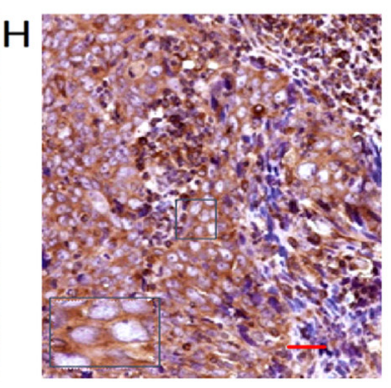

I
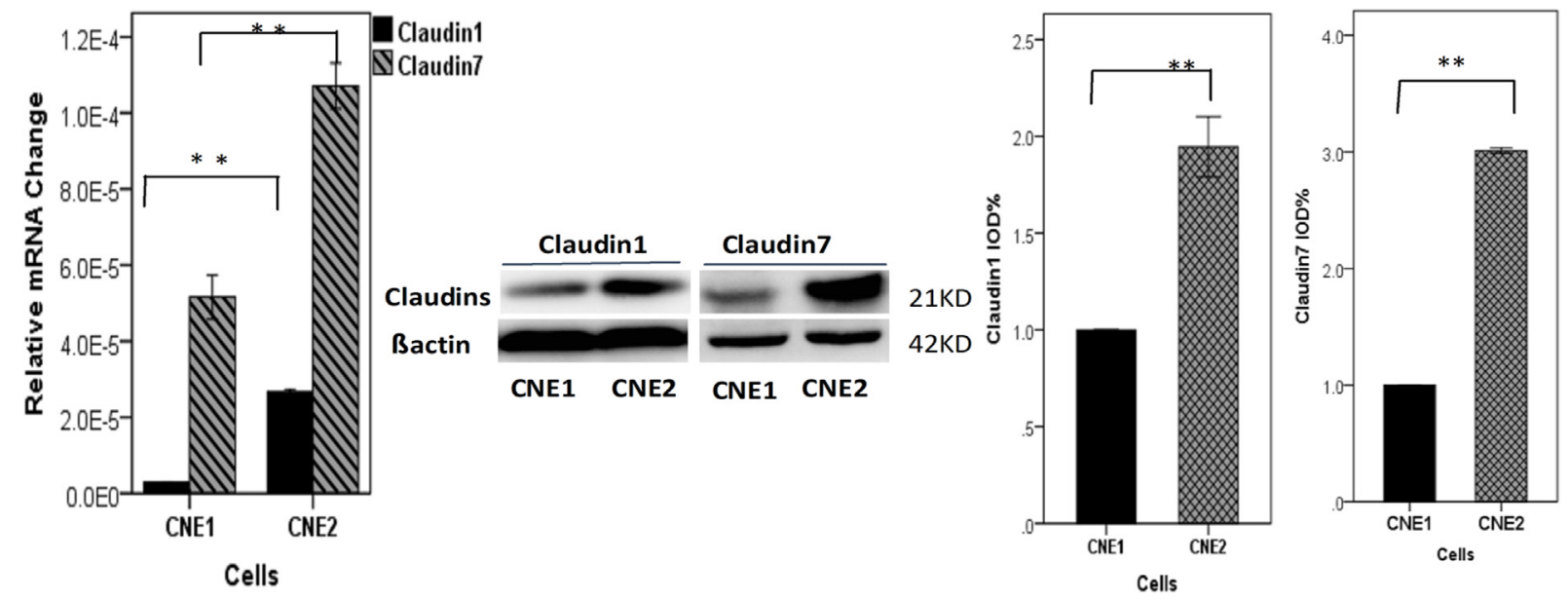

Figure 1: Brown staining demonstrates the expression and location of CLDN1. A-D. / CLDN7 (E-H) in nasopharyngeal carcinoma (NPC), and only membranous and/or cytoplasmic staining was classified as positive. A, E. Negative control of CLDN1/ $C L D N 7$. B, F. CLDN1/CLDN7 were highly expressed in the stratified squamous nasopharyngeal epithelium. C, G. CLDN1/CLDN7 were highly expressed in well-differentiated NPC tissues. D, H. CLDN1/CLDN7 were highly expressed in poorly differentiated NPC tissue. CLDN7 showed a much increased expression rate in the poorly differentiated NPC tissues H. compared to the well-differentiated NPCs G. I. Comparing the expression of CLDN1/CLDN7 in CNE1 and CNE2 cells based by RT-PCR and Western blotting: both were highly expressed in CNE2. Scale bar $=100 \mu \mathrm{m}$. **: $\mathrm{P}<0.05$. 
Table 1: Primers used for PCR

\begin{tabular}{lll}
\hline Gene & Sense & Antisense \\
\hline CLDN1 & 5'-CCCTATGACCCCAGTCAATG-3' & 5'-ACCTCCCAGAAGGCAGAGA-3' \\
CLDN7 & 5'-AGAGCACTTTGGACAGAACCC -3' & 5'-CTCCGGACTGGATTTCCCTC-3' \\
P18 & 5'-GCCGAGCCTCCTTAAAACTC-3' & 5'-GAGGGTGCCGGTTTCTTCT -3' \\
HIF1 $\alpha$ & 5'-ACCTATGACCTGCTTGGTGC -3' & 5'-GGCTGTGTCGACTGAGGAAA -3' \\
$\beta$-actin & 5'-TGGCACCCAGCACAATGAA-3' & 5'-CTAAGTCATAGTCCGCCTAGAAGCA-3 \\
\hline
\end{tabular}

Hypoxic condition triggered a decline in the $C L D N 7$ protein production in CNE1 and increased the expression in CNE2. Real-time PCR reflected the relative mRNA change more precisely, and the changes of CLDN1 and $C L D N 7$ were opposite in CNE2 cells (Figure 4E). CLDN7 and HIF $1 \alpha$ exhibited the same trend in both cells, which might be associated with their differentiation status.

P18, an important regulatory protein of cell differentiation $[39,40]$, can also affect cell proliferation by adjusting CDK $4 / 6$, inhibiting cells from transitioning from the G1 to S phase. To identify the potential relationship of P18 with CLDNI/7 and HIFI $\alpha$, we next investigated the changes of P18 in NPCs under the hypoxic conditions.

\section{Hypoxia stimulated changes in P18, which exhibited changes similar to $C L D N 7$ and HIF1a in NPCs}

Hypoxia conditions significantly promoted P18 protein expression in CNE2 cells and inhibited its expression in CNE1 cells, which changed similarly as CLDN7 and HIF $1 \alpha$ in NPCs (Figure 6A). The change was accompanied by a significant reduction of cell proliferation and viability, as demonstrated by EdU and MTT assays.

The analysis of the flow cell cycle was consistent with the change in P18 expression in both cell types. At the initial stage of hypoxia, both cells showed a partial $\mathrm{G} 1$ arrest and a decrease in the $\mathrm{S}$ phase fraction. With the development of hypoxia, the inhibitory effect on CNE1 was reduced, and the cell proliferation was accelerated (Supplementary Figure 1).

\section{HIF1 $\alpha$ may directly regulate the expression of $C L D N 1 / C L D N 7$ and further affect P18 expression through $C L D N 7$}

Using small interfering RNA transfection technique, we investigated the potential correlation between HIF $1 \alpha$ and $C L D N 1$, as well as $C L D N 7$ and P18 in NPCs. The siRNA sequences are shown in Table 2.

Knock down of HIF $1 \alpha$ in NPCs promoted CLDN1 expression and inhibited $C L D N 7$ expression at both the mRNA and protein levels, which may also indirectly affect the expression of $\mathrm{P} 18$ through the regulation of CLDN7. The silencing of $C L D N 7$ inhibited the expression of $\mathrm{P} 18$, which did not occur after HIF1 $\alpha$ or CLDN1 silencing (Figure 5B \& 5C).

\section{Correlation between $C L D N 1$ and $C L D N 7$}

The silencing of CLDN1 up-regulated the expression of $C L D N 7$, whereas the silencing of $C L D N 7$ inhibited the expression of $C L D N 1$ (Figure 5C). We used siRNA approach to reveal the causal link between $C L D N 1$ and $C L D N 7$, which demonstrated clearly in a lose-offunction analysis that $C L D N 7$ knockdown significantly reduced mRNA expression of CLDN1 (Figure 5C); in contrast, CLDN1 knockdown triggered CLDN7 up regulation (Figure $5 \mathrm{C}$ ). Western blot analysis provided further matching evidence of protein expression pattern between $C L D N 1$ and $C L D N 7$, that $C L D N 7$ knockdown reduced $C L D N 1$ protein level (Figure $5 \mathrm{G} \& 5 \mathrm{M}$ ). In contrast $C L D N 1$ knockdown triggered upregulation of CLDN7 (Figure 5F \& 5M), potentially through a negative feedback loop.

\section{Cycling hypoxia can inhibit invasion but promote the proliferation of CNE2 cells}

Cycling hypoxia resulting from transient fluctuations in tumor perfusion has received increasing attention in recent years. This was because of the significant influence on treatment resistance displayed by tumor cells as well as the endothelial cells of the tumor vasculature under hypoxia condition [33, 34]. Chronic hypoxia can significantly promote the invasion of CNE2 cells, and this phenomenon may persist in cycling hypoxia conditions.

We placed CNE2 cells in a hypoxia condition as shown above, and exposed the cells to cycling hypoxia to further investigate the expression of $C L D N S$ and $\mathrm{P} 18$ at $4 \mathrm{~h}, 8 \mathrm{~h}$, and $12 \mathrm{~h}$ in CNE2 cells with RT-PCR and western blot analysis. Cycling hypoxia significantly reduced the P18 expression in CNE1 and CNE2 at both mRNA and protein levels (Figure 6A). It also inhibited cell invasion by reducing the expression of $C L D N 7$ and up-regulating $C L D N 1$, and promoted cell proliferation by downregulating $P 18$ expression (Figure $6 \mathrm{~B} \& 6 \mathrm{C}$ ). 


\section{DISCUSSION}

$C L D N s$, as important components of TJs, contribute to the formation of epithelium barriers through interaction with other tight junction proteins. Their function in the development of cancers is mainly due to that some $C L D N s$ can also interact with non-tight junction proteins, including the cell adhesion proteins (EpCam and tetraspanins), the signaling proteins (ephrin $\mathrm{A}$ and $\mathrm{B}$ ) and their receptors (EphA and EphB, 32) The expression of $C L D N s$ differs in various organs $[1,11,36]$, Several articles have reported the correlation between CLDN1 \& CLDN7 on NPC cells, and demonstrated that CLDN7 may serve as a useful biomarker in the prediction of distant metastasis and patient survival in NPC [24, 25].
To our knowledge, the present study is the first to report the causal link between $C L D N S$ and NPC, in close association with the differentiation status of both NPC tissues and cells. Our results showed that poorly differentiated NPC tissue and cells had a high expression of CLDN7.

In many epithelial cells, claudin-7 had among the strongest polymerization propensity, claudin-7 is localized not at the tight junction, but on the lateral call membrane, without associated lateral strands [26]. Heiler and colleagues demonstrated that palmitoylated CLDN7 supports metastasis of HEK cells through association with MMP14 and CD147 [26]. A recently study by Thuma and colleagues further reported that nonpalmitoylated $C L D N 7$ is required for the formation of intercellular
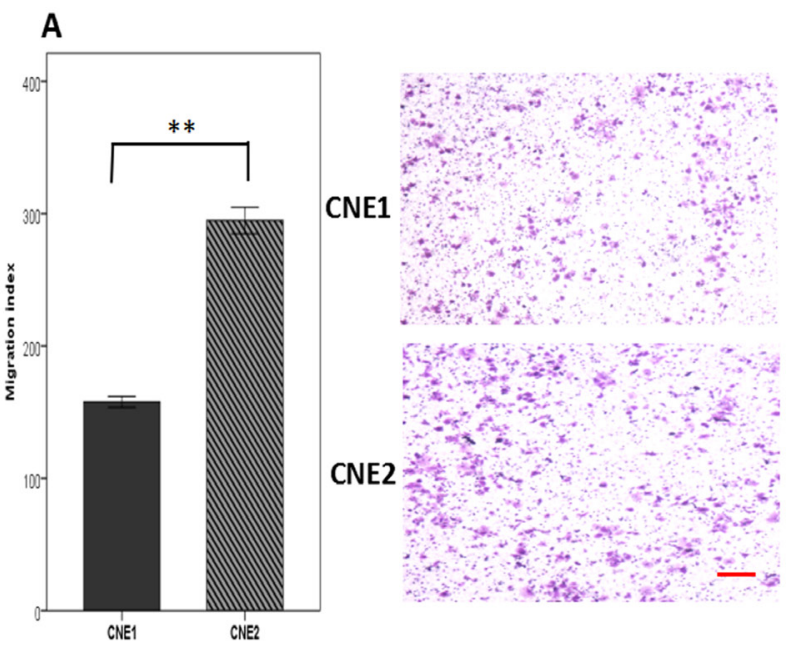

C

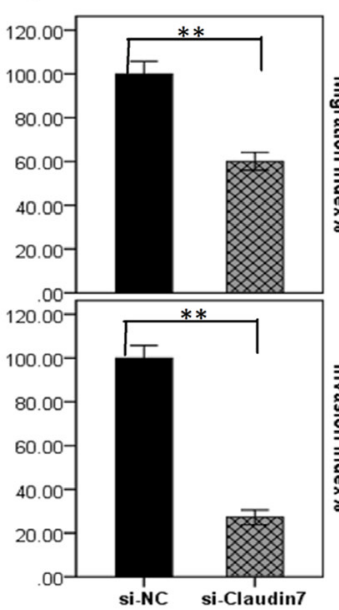

D

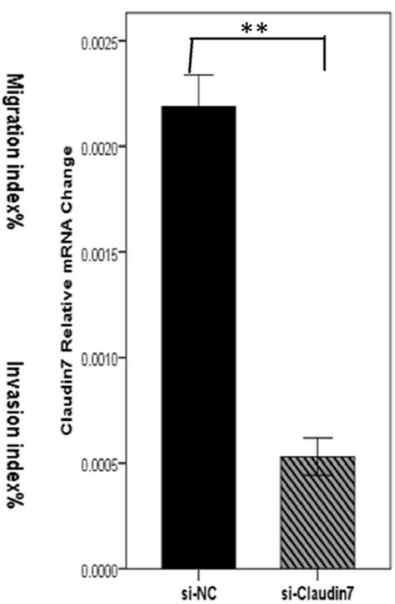

B

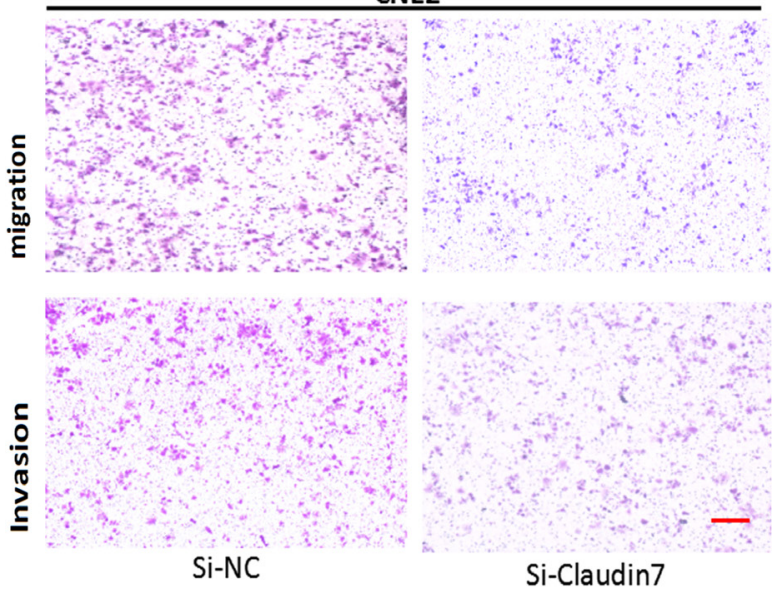

Si-Claudin7

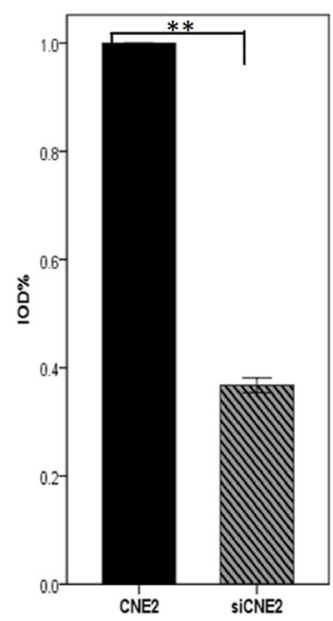

Figure 2: A. Migration index analysis of CNE1 and CNE2 using transwell model showed that CNE2 cells with high CLDN7 expression had a significantly increased migration ability than CNE1 cells. D. RT-PCR and Western blotting showed the results of knocking down CLDN7 in CNE2; the Si-RNA silencing efficiency was approximately 60-70\%. B, C. Migration and invasion results of Si-NC and siClaudin7 in CNE2 demonstrated that knocking down the CLDN7 expression inhibited the migration and invasion ability of CNE2 cells. $\mathrm{Si}-\mathrm{NC}$ is the negative control of silencing the expression of CLDN7 in CNE2. All statistical analysis were compared to the control. Scale bar $=100 \mu \mathrm{m} . * *: \mathrm{P}<0.01$. 
Table 2: siRNA sequences

\begin{tabular}{lll}
\hline Gene & Sense & Anti-sense \\
\hline si-HIF1 $\alpha$ & 5'-GGCCGCUCAAUUUAUGAAUTT-3' & 5'-AUUCAUAAAUUGAGCGGCCTT-3' \\
si-CLDN1 & 5'-CCAUGGGUGGAGGCAUAAUTT-3' & 5'-AUUAUGCCUCCACCCAUGGTT-3' \\
si-CLDN7 & 5'-GGCAUAAUUUUCAUCGUGGTT-3' & 5'-CCACGAUGAAAAUUAUGCCTT-3' \\
si-con & 5'-UUCUCCGAACGUGUCACGUTT-3' & 5'-ACGUGACACGUUCGGAGAATT-3' \\
\hline
\end{tabular}
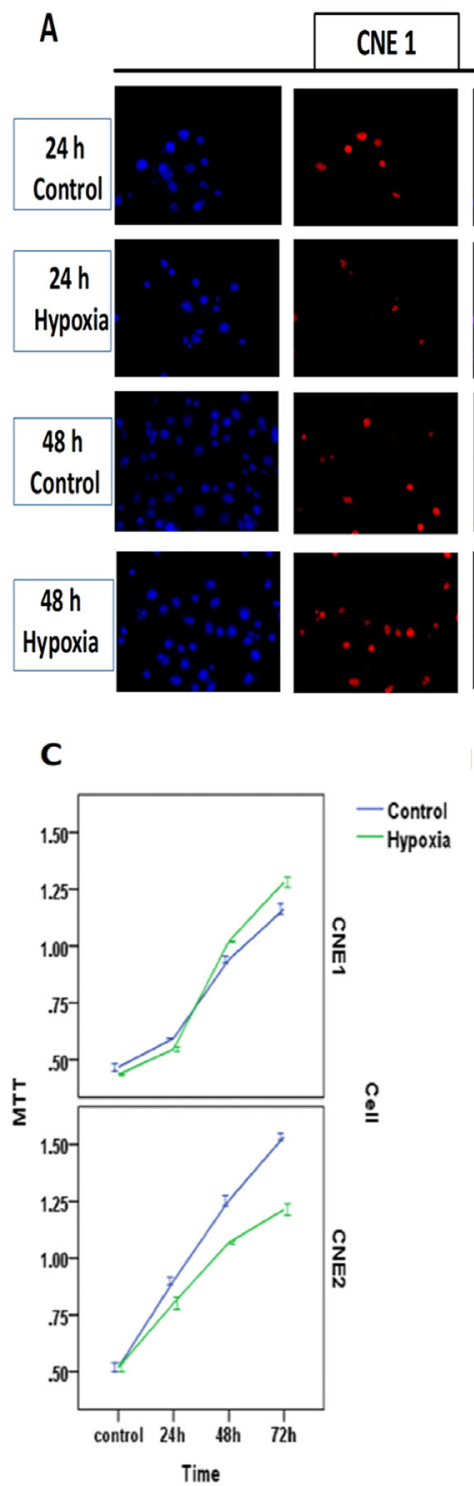
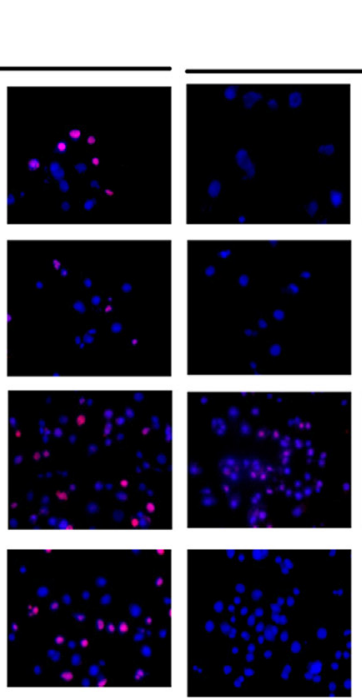

CNE2
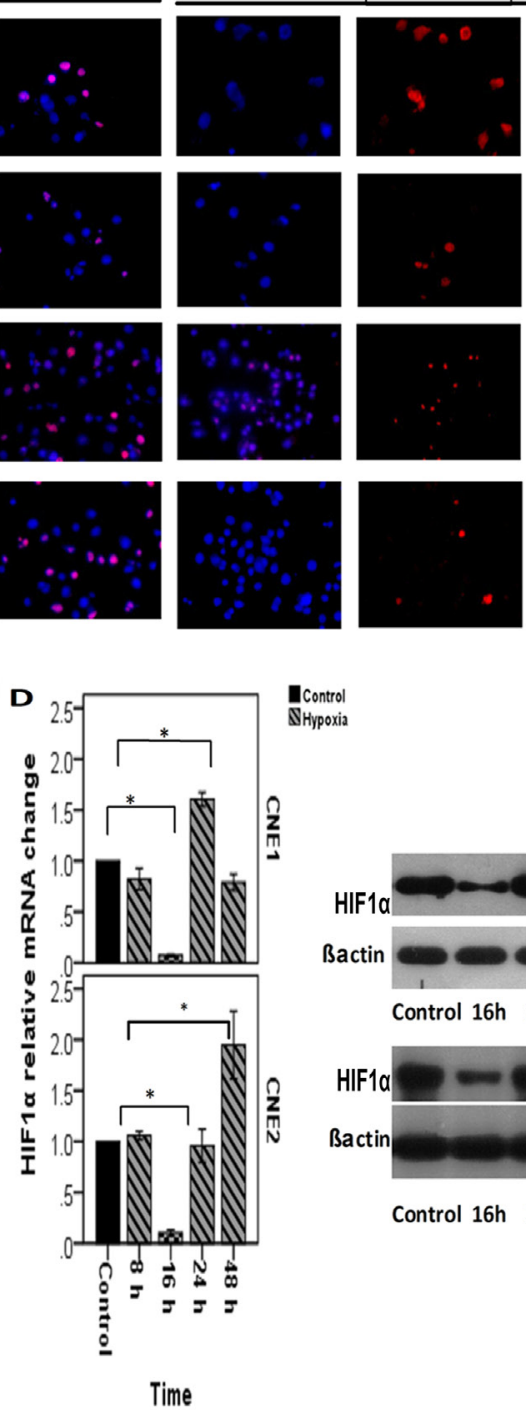

B
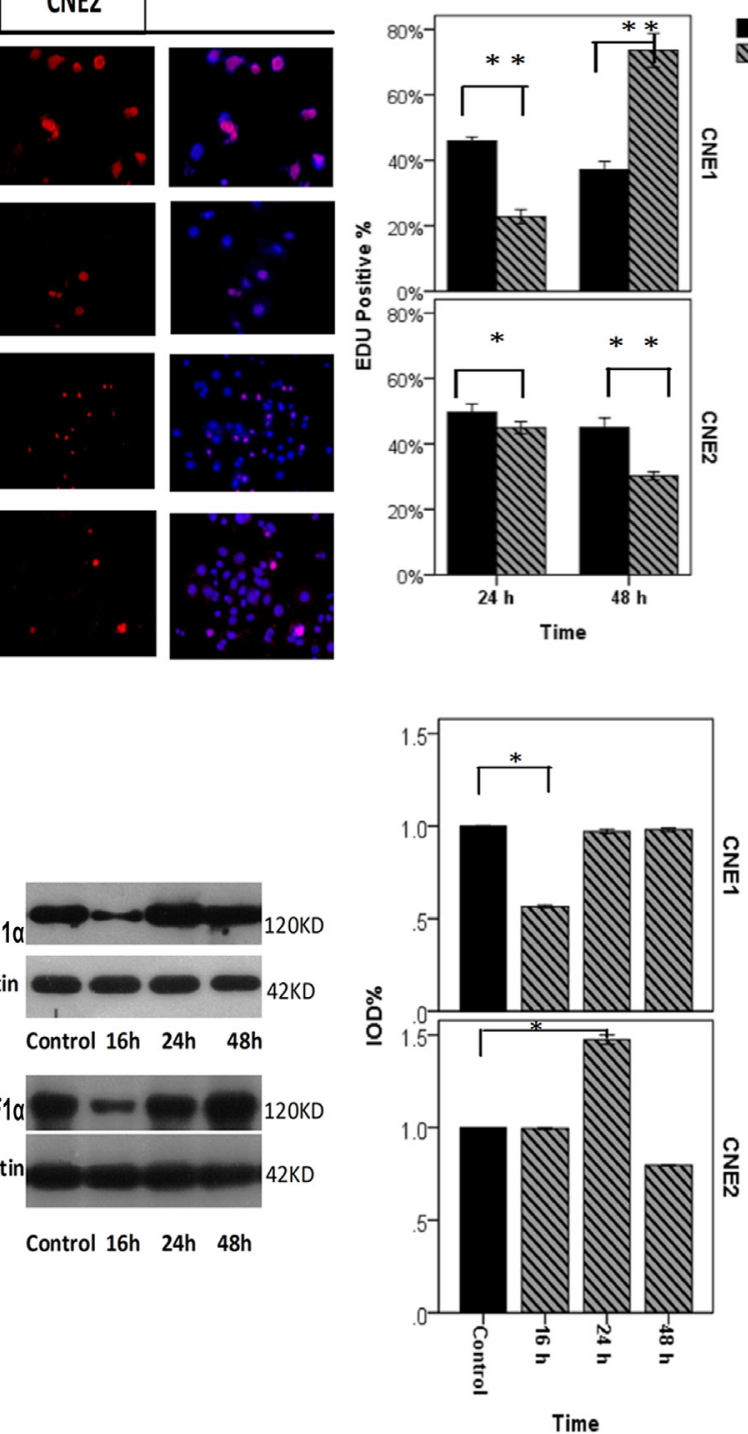

Control

SHypoxia
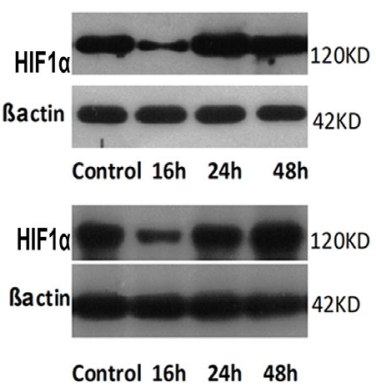

Control $16 \mathrm{~h} 24 \mathrm{~h} 48 \mathrm{~h}$

Time

Figure 3: NPCs incubated in a hypoxic atmosphere of $0.1 \% \mathrm{O}_{2}, 5 \% \mathrm{CO}_{2}$, and $94 \% \mathrm{~N}_{2}$ at $37^{\circ} \mathrm{C}$ for different amounts of time. A, B. EdU of CNE1 shows that hypoxic conditions inhibited CNE1 proliferation before $24 \mathrm{~h}$, whereas it may be promoted after $24 \mathrm{~h}$. EdU of CNE2 shows that hypoxic conditions inhibited CNE2 proliferation. C. MTT of CNE1 shows the cell viability, and hypoxic conditions inhibited it at $24 \mathrm{~h}$, whereas it may be promoted after $24 \mathrm{~h}$. The MTT assay of CNE2 showed that hypoxic conditions can significantly inhibit cell viability and decrease the migration and invasion ability of CNE1 cells. D. RT-PCR showed the HIF1 $\alpha$ relative mRNA change in CNE1, which experienced a down-regulation at $16 \mathrm{~h}$ and then increased and reached a peak at $24 \mathrm{~h}$. RT-PCR showed the HIF $1 \alpha$ relative mRNA change in CNE2, which experienced a decline at $16 \mathrm{~h}$ and then increased gradually and reached the peak at $48 \mathrm{~h}$. The HIF1 $\alpha$ protein change in CNE1, which decreased at $16 \mathrm{~h}$ significantly. Although the mRNA was increased at $24 \mathrm{~h}$, HIF1 $\alpha$ protein was not significantly changedcomparedwith the control. HIF1 $\alpha$ protein change in CNE2, which decreased at $16 \mathrm{~h}$ then increased and reached the peak at $48 \mathrm{~h}$ gradually, which was higher than control. 
TJs as a TJ protein, as well as inhibiting the tumor metastasis via cytoskeletal keratin and myosin association with EpC, a cancer-initiating cells marker. However, glycolipid-enriched membrane microdomains (GEM)located palmitoylated CLDN7 can promote cell motility through association with the cytoskeletal linker proteins actinin, moesin and RhoA, which are engaged in actin cytoskeleton or ganization. CLDN7 palmitoylation can promote cell invasion by association with uPAR, MMP14 and CD147, and also play a role in epithelial-mesenchymal transition (EMT) of pancreatic adenocarcinoma cells [27]. These studies contribute enormous understanding of the mechanistic role of CLDN7 in promoting tumor motility and metastasis.

We speculate that CLDN7 may promote metastatsis of NPC cells based on its palmitoylation status. We showed in this study that knockdown CLDN7 non-selectively with SiRNA on NPC cells triggered down regulation of both

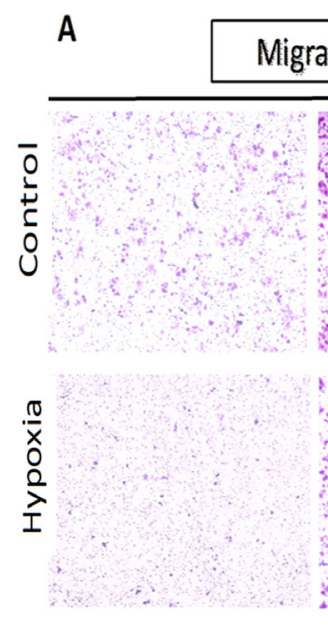

CNE1

D

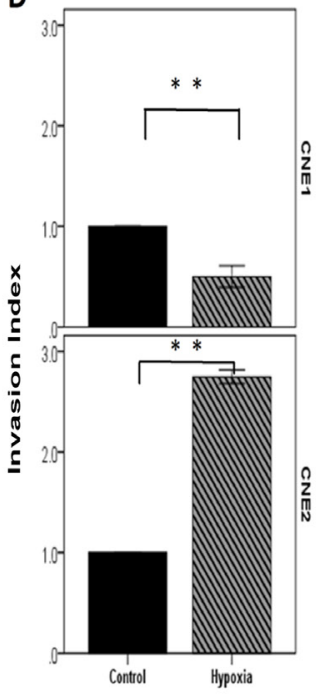

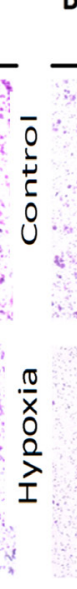

B
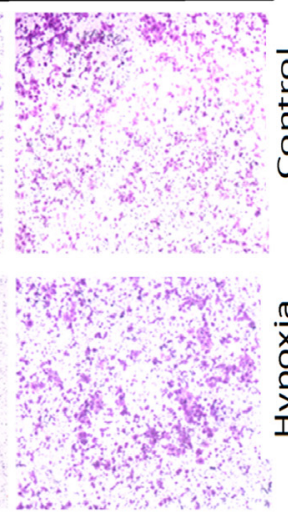

CNE2

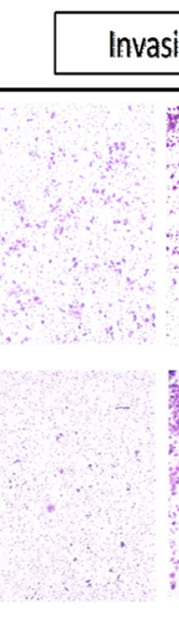

CNE1

\section{Invasion}

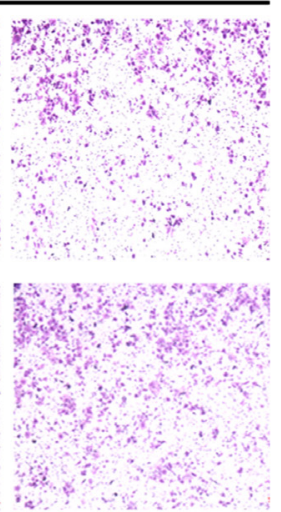

CNE2
C
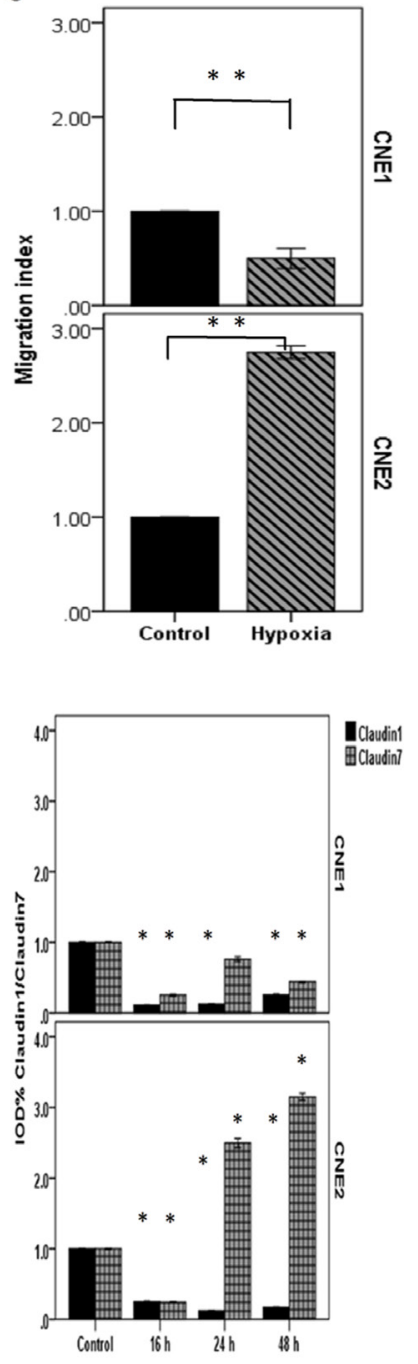

Figure 4: NPCs incubated in a hypoxic atmosphere of $0.1 \% \mathrm{O}_{2}, 5 \% \mathrm{CO}_{2}$, and $94 \% \mathrm{~N}_{2}$ at $37^{\circ} \mathrm{C}$ for different amounts of time. A, B. Images of the migration and invasion experiments of the NPCs conducted using transwell model. Compared with the control, the number of cells was significantly reduced in the hypoxic conditions in CNE1 cells and significantly increased in CNE2 cells. C, D. Bar graphs showing the transwell experiment results of CNE1 and CNE2. E. RT-PCR showed the CLDN1/CLDN7 relative mRNA change in CNE1, and both experienced decreases before $16 \mathrm{~h}$ and then increased. The mRNA of CLDN1 increased sharply and reached the peak at 24 $\mathrm{h}$, which was two-fold higher than the control, but it declined significantly thereafter. CLDN7 expression gradually increased, but it did not reach the control level by $48 \mathrm{~h}$. The CLDN1/CLDN7 relative mRNA change in CNE2 cells. CLDN1 increased and reached the highest level at $8 \mathrm{~h}$, after which it declined sharply at $16 \mathrm{~h}, 24 \mathrm{~h}$ and $48 \mathrm{~h}$. CLDN7 decreased at $8 \mathrm{~h}$ and $16 \mathrm{~h}$ then increased to higher expression than the control at $24 \mathrm{~h}$ and reached the peak at $48 \mathrm{~h}$. The proteins of CLDN1 and CLDN7 in CNE1 cells both decreased significantly compared with the control. Although the mRNA of $C L D N 1$ was increased at $24 \mathrm{~h}$, the protein did not increase after that point. The proteins of $C L D N 1$ and $C L D N 7$ in CNE2 both decreased at $16 \mathrm{~h}$ then increased at $24 \mathrm{~h}$ and reached the peak at $48 \mathrm{~h}$. All positive. *: $\mathrm{P}<0.05$, all data were compared to the control. 
palmitoylated and non-palmitoylated CLDN7, as well as a clear reduction of tumor cells metastasis. we speculate that NPC with a high expression of CLDN7 especially the palmitoylated $C L D N 7$ may also cause correspondent changes in MMPs to assist the tumor cells invasion, which requires further evidence to approve. We shall further investigate the palmitoylation status and intracellular localisation in the regulation of NPC development and metastasis: once confirmed, palmitoylated CLDN7 can be used as an indicator of NPC metastasis, and will become a new therapeutic target to inhibit cancer cell invasion and cancer recurrence.

Furthermore, CLDN1 and CLDN7 could affect the expression of each other in NPCs: silencing of the CLDN7 inhibited CLDN1 expression; in contrast, $C L D N 7$ expression was significantly up-regulated when
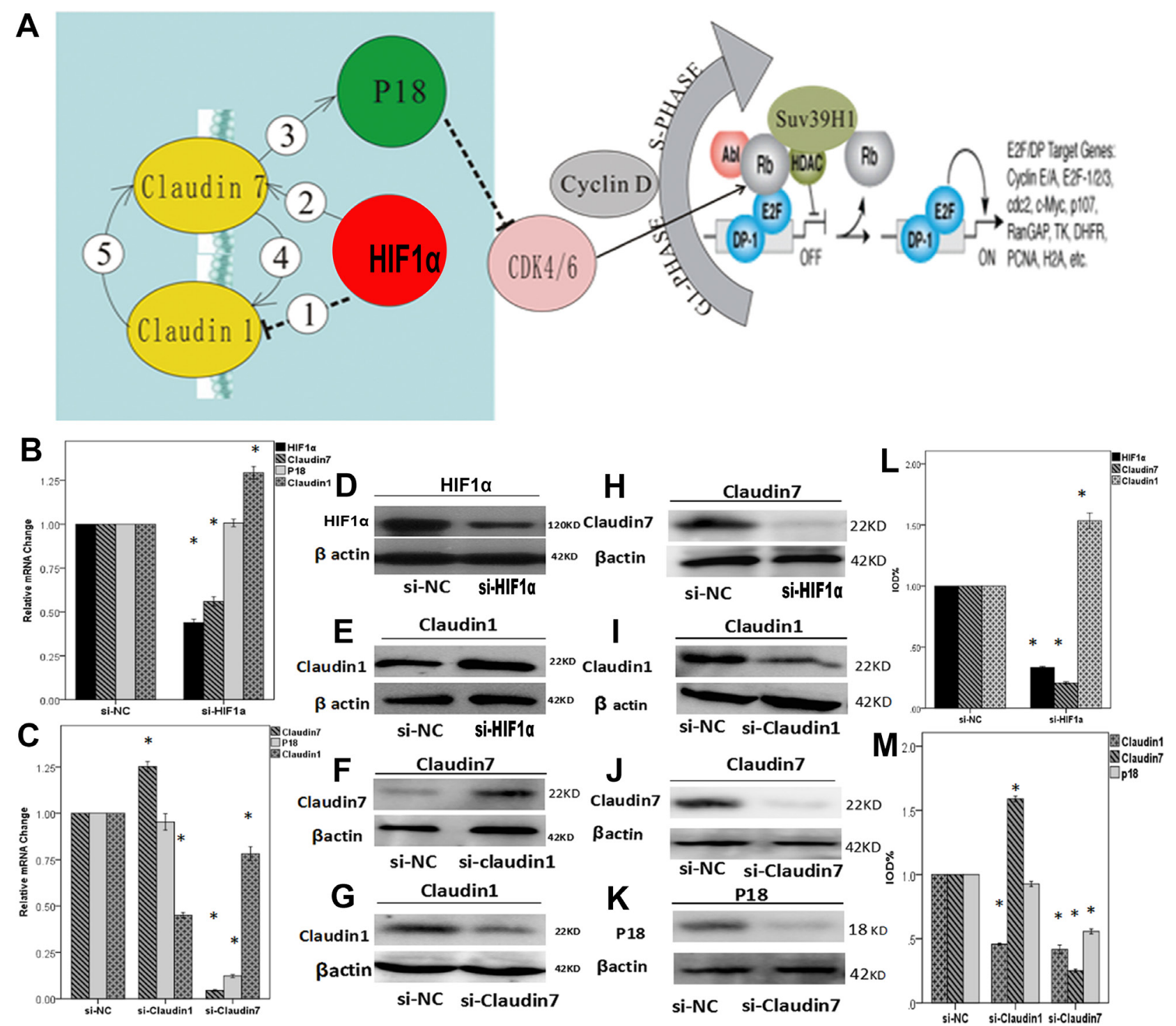

Figure 5: A. Diagram showing related genes association in the cell signaling pathway. In NPCs, hypoxia condition enhances the expression of HIF $1 \alpha$ and further up-regulate $C L D N 7$ 2, which consequently stimulates the expression of P18 (3) and other downstream effectors. HIF $1 \alpha$ also down-regulates $C L D N 1$ (1) potentially through $C L D N 7$. There could be a feedback regulation between CLDN1 and CLDN7: CLDN7 positively regulates $C L D N 1$ (4), whilst $C L D N 1$ negatively modulates the expression of $C L D N 7$ as a negative feedback loop (5). B-M. RT-PCR and western bloting analysis to reveal the interactions between HIF1 $\alpha, C L D N 1, C L D N 7$ and P18. (B) Quantification analysis showed that knock down HIFl $\alpha$ could down-regulate the mRNA expression of CLDN7 but promote CLDN1 up-regulation. Si-HIF1 $\alpha$ can not directly affect the expression of $P 18$. (C) Silencing CLDN1 enhanced the expression of CLDN7 and did not affect P18. In comparison, silencing $C L D N 7$ down-regulated the expression of CLDN1 and P18. (D) Western blotting result showed that silencing HIF1 $\alpha$ triggered downregulation of HIF1 $\alpha$ protein (D\&L), up-regulation of claudin1 (E\&L), and down-regulation of claudin7 (H\&L). Silencing CLDN1 triggered down-regulation of claudin 1 (I\&M), and at the same time an up-regulation of claudin7 (F\&M). In contrast, silencing CLDN7 greatly reduced claudin7 protein expression (J\&M), and triggered a much reduced claudin1 (G\&M) as well as P18 expression (K\&M). Si-NC is the negative control of silencing the relative genes in CNE2. *: $\mathrm{P}<0.05$, all data were compared to the control. 
CLDN1 was knocked down, strongly suggesting a potential negative regulatory feedback between $C L D N 1$ and $C L D N 7$. Up-regulated $C L D N 1$ expression in NPCs confers resistance to cell death [18]. CLDN1 knockdown promoted the migration related pathway in MKN28 cells, which includes MMP7, TNF-SF10, TGFBR1, and CCL2 [16]. Nm23H1 mediates tumor invasion in esophageal squamous cell carcinoma by regulation of CLDN1 through the AKT signalling [45]. In consistence with these previous reports, our results suggest that the CLDN1-dependent pathway might also be involved in NPC progression.

HIF $1 \alpha$ has been commonly recognized as an independent prognostic factor of NPC, since hypoxia could promote NPC progression $[37,38]$. By placing NPCs in a $0.1 \% \mathrm{O}_{2}$ incubator, we mimicked the hypoxic condition similarly as in vivo in this study, to reveal the correlation between hypoxia and $C L D N 1$ / CLDN7. Hypoxia affects
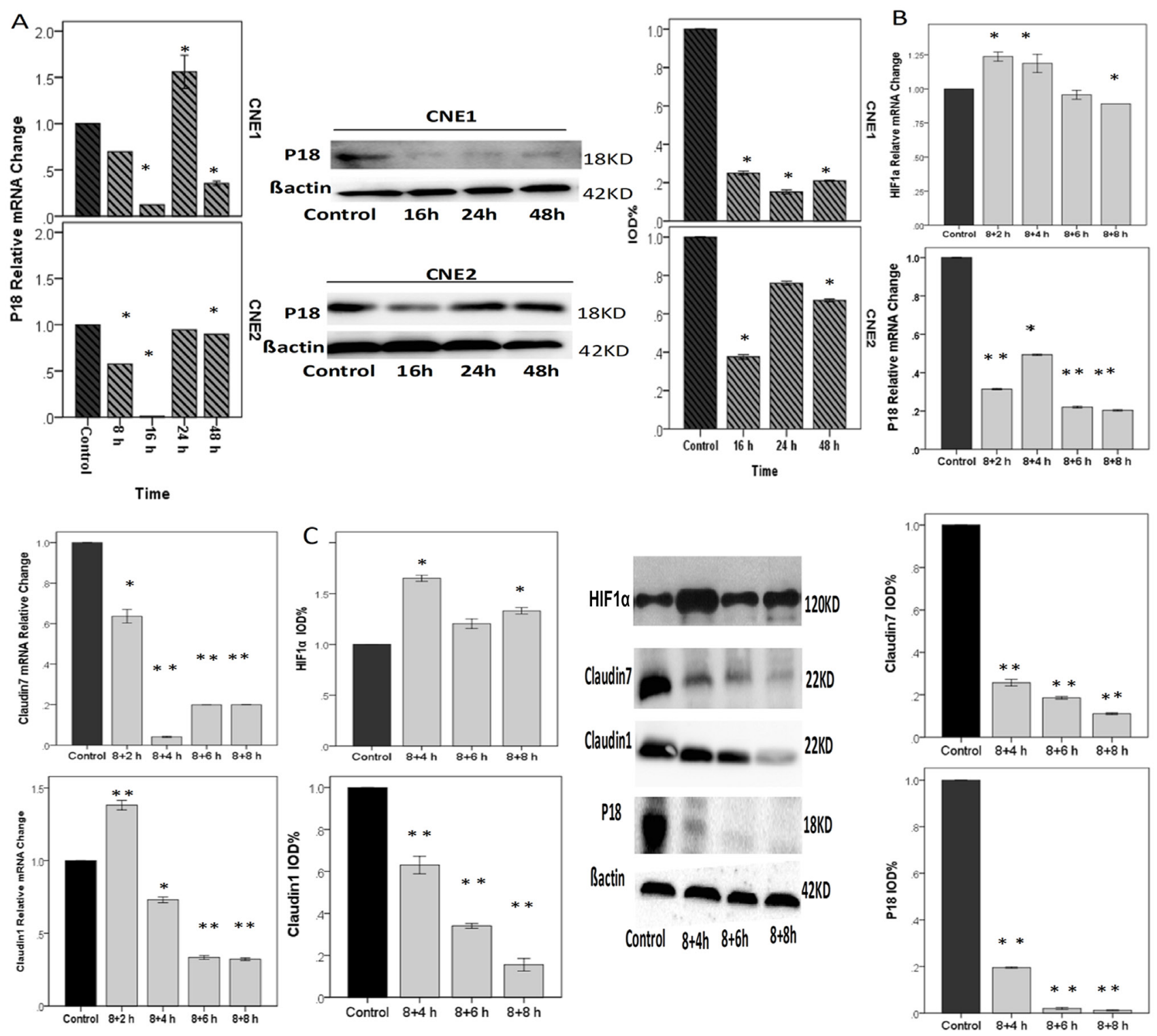

Figure 6: NPCs treated with cycling hypoxia conditions with 8 h hypoxia, followed by culturing in $20 \% \mathrm{O}_{2}$ for 2 h, 4 h, 6 h, or 8 h. A. P18 relative mRNA and protein change in CNE1 and CNE2 cells were decreased. P18 and CLDN1 had the same trend of expression changes in CNE1 cells (please refere to Figure 4E). In CNE2 cells, p18 declined to the minimum at $16 \mathrm{~h}$ and then increased gradually. B \& C. RT-PCR and Western blotting showed the relative gene and protein expression changes under cycling hypoxia condition. HIF $1 \alpha$ relative mRNA change: although we did not find a positive change of reoxygenation to the control, there are differences between $8+2 \mathrm{~h}$ and $8+8 \mathrm{~h}$, and between $8+4 \mathrm{~h}$ and $8+8 \mathrm{~h}(\mathrm{p}<0.05)$. P18 relative mRNA change: Compared with the control, cycling hypoxia conditions significantly inhibited the expression of P18. CLDN1 relative mRNA change was up-regulated at $2 \mathrm{~h}$ after reoxygenation, and then significantly declined. CLDN7 relative m RNA change. Cycling hypoxia conditions inhibited the expression of $C L D N 7$ dramatically. $*: \mathrm{P}<0.05 ; * *: \mathrm{P}<0.01$. All data were compared to the control. 
NPC invasion and migration by affecting the expression of CLDN7. Our study has shown that knocking down $H I F 1 \alpha$ in NPCs promotes the expression of $C L D N 1$ and inhibits $C L D N 7$ at protein levels. We speculate that HIF $1 \alpha$ may be an upstream activator regulating CLDN1 and CLDN7. If the above speculation is correct, however, both HIF $1 \alpha$ and CLDN1 should decrease at the same time in CNE1 under the hypoxia condition. The opposite phenomenon observed in this study can be explained by the negative feedback regulation between $C L D N 1$ and $C L D N 7$. The reduced expression of $H I F 1 \alpha$ in CNE1 can promote CLDN1 and decrease CLDN7, whereas the inhibition of CLDN7 can further down-regulate CLDN1 (Figure 5). Compared with the change of HIF $1 \alpha$, which quickly returned to normal levels after only a transient decrease, the CLDN7 reduction was more persistently recorded (Figure 4A); therefore, the combined effect is that CLDN1 expression is decreased.

The sensitivity of NPCs to a hypoxic environment is associated with the differentiation status of the cells. Hypoxia can promote the proliferation of CNE1 cells, whilst inhibit CNE2 cell proliferation. P18 is a gene associated with cell differentiation [39, 40] which influences CDK4/6, and inhibits cells transformation from $\mathrm{G} 1$ to $\mathrm{S}$ phase, thereby affecting cell proliferation. P18 expression in NPCs was consistent with the cell proliferation assay and the flow cytometry analyses (Supplementary Figure 1). However, after silencing $H I F 1 \alpha$, there was no direct correlation between HIF $1 \alpha$ and P18. To our surprise, a decline of CLDN7 led to decreased expression of P18 (Figure 5). Therefore, we speculate that HIF $1 \alpha$ could indirectly affect the expression of P18 by regulating $C L D N 7$, thereby affecting cell proliferation and metastasis. In summary, HIF $1 \alpha$ may directly regulate the expression of $C L D N 1 / C L D N 7$ and further regulate $\mathrm{P} 18$ through CLDN7.

Cycling hypoxia resulting from transient fluctuations in tumor perfusion has received increasing attention. This is because of the significant influence in treatment resistance displayed by tumor cells, as well as the endothelial cells of the tumor vasculature [33, 34]. In 1996, Kimura et al. demonstrated that in renal cancer tissue intermittent blood cells could pass through the cancer lesions [41]. By testing bleeding in different parts of solid cancers, Hironobu et al. found that the anoxia is mostly due to cycling hypoxia, and the period of anoxia and oxygen richness is determined by the type of cancer tissues and sites [42]. Cycling hypoxia can promote cancer invasion, metastasis and treatment resistance, because once the pressure of hypoxia is lifted, mRNA silencing particles are released from the pressure, leading to excessive translation of certain regulatory proteins [43]. However, in contrary to our expectation, our results showed that cycling hypoxia could inhibit cell invasion by reducing the expression of CLDN7. Mathieu et al. proposed that cycling hypoxia could trigger cancer cells reprogramming (iPSC induction) to change their metabolism from oxidative to highly glycolytic status early in the process [44]. We speculate that the change of CLDN7 may be associated with remodeling and differentiation of NPCs when exposed to cycling hypoxia. Therefore, reoxygenation could potentially increase $C L D N 1$ expression and decrease P18, suggesting a correlation between these genes.

Our results also suggest that potentially we could use the characteristics of the tumor center and cycling fluctuations of angiogenesis / bleeding to inhibit metastasis and invasion of tumors, by regulating the timing and pattern of cycling hypoxia. If such experiments can be proved in vivo in animal models, it may potentially be used as a new treatment for solid tumors, especially those that are not sensitive to radiotherapy.

\section{MATERIALS AND METHODS}

\section{Cells and reagents}

NPC cells CNE1 and CNE2 were purchased from China Tumor Cell Institute, Beijing, China. The following antibodies $(\mathrm{Ab})$ were used: rabbit polyclonal $\mathrm{Ab}$ for CLDN1/CLDN7 (ab15098/ ab27487, Abcam, Cambridge, MA, USA), mouse monoclonal Ab P18 (ab80625, Abcam Cambridge, MA, USA), and mouse monoclonal Ab for HIF1- $\alpha$ (sc-53546, Santa Cruz Biotechnology, INC). Hypoxic conditions were generated using a hypoxia workstation (Ruskin Technologies, UK).

\section{Immunohistochemistry}

Immunohistochemical analysis was performed to evaluate the CLDN1/CLDN7 protein expression and the correlation between tumor cell differentiation on 66 NPCs samples. The result was analyzed by Pearson's chi-square test. Written consent was obtained, and ethical approval was granted by the Regional Research Ethics Committee (permission number: 20140993). Primary antibodies against CLDN1/CLDN7 (1:200) were used. The negative controls were handled in the same way as the experimental samples, except that PBS was applied instead of the primary antibodies. Experiments were performed in accordance with the instructions of the Streptomycin Peroxide Kits (sigma-Aldrich, USA). Brown membranous and/or cytoplasmic staining was classified as positive expression. Immunostaining was observed and imaged under light microscopy. Positive / negative cells and the total cells from minimum five randomly chosen visual fields were counted in each specimen. The quantification was represented by the percentage of positively stained tumor cells, and graded as less than $10 \%(1+), 10-50 \%(2+)$, or more than $50 \%(3+)$. The staining intensity was recorded as absent $(0)$, weak $(1+)$, moderate $(2+)$, or strong $(3+)$. The 2 scores were multiplied to generate a final score of 0 to 9 [24]. 


\section{Cell culture}

The NPC cell lines CNE1 and CNE2 were cultured in 1640 medium supplemented with $10 \%$ fetal bovine serum (FBS), $100 \mathrm{U} / \mathrm{ml}$ penicillin and $100 \mu \mathrm{g} / \mathrm{ml}$ streptomycin (Life Technologies, Carlsbad, CA, USA) at $37^{\circ} \mathrm{C}$ and $5 \% \mathrm{CO}_{2}$ in an incubator. To mimic severe hypoxic conditions, cells were cultured at $37^{\circ} \mathrm{C}$ in $5 \%$ $\mathrm{CO}_{2}, 94.9 \% \mathrm{~N}_{2}$, and $0.1 \% \mathrm{O}_{2}$ atmosphere in a hypoxia incubator (Ruskin Technologies, UK).

\section{Cell viability assay}

Cell viability was examined with MTT assay according to the manufacturer's instructions. A total of $2 \times 10^{3}$ cells/well was incubated for 24,48 or $72 \mathrm{~h}$ in $96-$ well plates at a final volume of $100 \mu \mathrm{l} /$ well. After the addition of $10 \mu \mathrm{g} / \mathrm{well}$ of the MTT reagent, the cells were further incubated for $4-6 \mathrm{~h}$ in a $37^{\circ} \mathrm{C}$ incubator and then agitated for $10 \mathrm{~min}$ on a shaker. The cell number was determined based on the standardization from control cells used in the experiment. We then measured the absorbance of the samples at $490 \mathrm{~nm}$ (reference wavelength: $690 \mathrm{~nm}$ ) against the background control, using a 96-well plate reader.

\section{Cell proliferation assay}

Cells were seeded at $2 \times 10^{3}$ cell/well in poly-Dlysine coated $96-$ well chamber slides. Two hours prior to the end of the culture, $20-\mu \mathrm{m}$ EdU was added from a $100 \mathrm{mM} \mathrm{1:10} \mathrm{DMSO} / \mathrm{H}_{2} \mathrm{O}$ stock. Cells were then fixed for $20 \mathrm{~min}$ in 4\% PFA in PBS, and EdU was detected according to the protocol (KGA 337-100, KeyGEN BioTECH, Nanjing, China). The cell proliferation was quantified as the percentage of EdU incorporating cells against the total number of cells determined by DAPI nuclear staining. Organotypic cultures were sectioned prior to detection of EdU incorporating cells per square millimeter of section, with section area being determined in Image J. The measurement of the detected areas was calibrated across various sizes of organotypic cultures.

\section{Transwell migration assay}

The cell migration assay was conducted using a cell migration assay system (CBA-100, Cell Biolabs, Inc., San Diego, CA, USA) equipped with 8 - $\mu \mathrm{m}$ pore size migration chambers [30]. The methods used in this assay were similar to the Matrigel invasion assay, except that the transwell insert was not coated with Matrigel. After $24 \mathrm{~h}$ of incubation, the migrated cell numbers were calculated. For each experiment, the number of cells from a minimum of five randomly chosen fields of each filter was quantified, and these experiments were independently performed at least three times.

\section{Invasion assay}

An invasion assay was performed using a BD BioCoat Growth Factor Reduced Matrigel Invasion Chamber (354483, BD Biosciences, San Jose, CA, USA) according to the manufacturer's instructions. Cells were starved in 1640 medium without FBS for $24 \mathrm{~h}$ and then plated on the upper insert at $2.5 \times 10^{4} /$ well and incubated in 1640 medium with FBS in $20 \%$ or $0.1 \%$ oxygen cell chambers, respectively. After a 24-h incubation, the non-invading cells remained on the upper surface of the membrane in each insert were gently removed. Cells that had penetrated through to the bottom surface of the membranes were fixed in $100 \%$ methanol and stained with $0.05 \%$ Toluidine Blue Solution (206-14555, Wako Pure Chemical Industries Ltd.). For each experiment, the number of cells in seven randomly chosen fields of each filter was quantified, and these experiments were independently performed at minimum of three times.

\section{Flow cytometry}

The cells were incubated in 6-well plates overnight, before synchronized next morning. The cells were treated with nacodazole (Life Technology, USA) in serum free / antibiotics free medium at $150 \mathrm{um} / \mathrm{ml}$ for $12 \mathrm{~h}$ [31], then replaced with hypoxia culture condition with fresh culture medium containing 10\% FBS and penicillin / streptomycin. Cells were harvested, washed once, and fixed in $75 \%$ ethanol at $4^{\circ} \mathrm{C}$ overnight. The cells were then washed 3 times with PBS, harvested and incubated in PBS suspension containing $5 \mu \mathrm{g} / \mathrm{ml}$ propidium iodide (P3566, Molecular Probes, Eugene, OR, USA) for $30 \mathrm{~min}$ at room temperature. The samples were then analyzed with a FACS flow cytometer (BD FACS Calbur TM).

\section{Quantitative RT-PCR}

Total RNA was extracted from the cells using TRIzol (Invitrogen, USA) following the manufacturer's instructions. One microgram of total RNA was subjected to reverse transcription to synthesize cDNA using the PrimeScript $\mathrm{RT}^{\mathrm{TM}}$ reagent reverse Kit (TaKaRa, Japan) for $15 \mathrm{~min}$ at $37^{\circ} \mathrm{C}$ and $5 \mathrm{~s}$ at $85^{\circ} \mathrm{C}$. The PCR program started with an initial denaturation at $95^{\circ} \mathrm{C}$ for $30 \mathrm{~S}$, followed by 40 cycles $\left(95^{\circ} \mathrm{C}\right.$ for $5 \mathrm{~s}, 60^{\circ} \mathrm{C}$ for $\left.30 \mathrm{~s}\right)$, and 1 $\mu \mathrm{g}$ of cDNA was used for the PCR. HIF $1 \alpha$ and Claudin 7 were amplified along with $\beta$-actin as an internal control following the instructions of the SYBR Premix Ex Taq ${ }^{\mathrm{TM}}$ II (TaKaRa, Japan). The PCR reaction conditions and the primer sequences of HIF1 $\alpha$, Claudin-7, and $\beta$-actin are shown in Table 1.

\section{RNA interference by synthetic siRNA}

Selective targeting of HIF $1 \alpha, C L D N 1, C L D N 7$ and p18 was performed using specific siRNAs. As a control, 
an siRNA sequence (si-NC) was employed that does not target any gene in the human genome and has been tested by microarray analysis (Dharmacon, Chicago, IL, USA). The siRNAs were synthesized commercially (Biomers. net GmbH, Ulm, Germany). The sequences are shown in Table 2. Transfection of the siRNA (final concentration $100 \mathrm{nM}$ ) was performed with Lipofectamine 2000.

\section{Western blotting}

Cells were washed with ice-cold PBS, harvested and lysed in lysis buffer and $0.1 \%$ PMSF (KAIJI, Nanjing, China). The protein concentration of the supernatant was determined with a BCA protein assay kit according to the manufacturer's instructions. Proteins were separated by SDS/PAGE and were transferred to polyvinylidenedifluoride membranes (Amersham).

\section{Statistical analyses}

All values are reported as the mean \pm SEM from minimum three independent experiments, unless otherwise stated. Two-sided Student's unpaired t test was used for the statistical analyses. ${ }^{*} * \mathrm{p}<0.01 ; *, \mathrm{p}<0.05$.

\section{CONFLICTS OF INTEREST}

We declare that the authors have no financial and personal conflict of interest with other people or organizations that can inappropriately influence this work. There is no professional or other personal interest of any nature or kind in any product, service and/or company that could be construed as influencing the position presented in, or the review of the manuscript entitled.

\section{Authors' contributions}

H.L. designed and performed experiments, analysed data and wrote the paper. F.J., J.L. and H.G. provided technical support, X.J. and A.Y. contributed with the experiment design, E.L. assisted with the hypoxia experiments, Y.W. provided financial support for the project.

\section{REFERENCES}

1. Hewitt KJ, Agarwal R, Morin PJ. The claudin gene family: expression in normal and neoplastic tissues. BMC Cancer 2006; 6:186.

2. Kominsky SL. Claudins: emerging targets for cancer therapy. Expert Rev Mol Med 2006; 8:1-11.

3. Swisshelm K, Macek R, Kubbies M. Role of claudins in tumorigenesis. Adv Drug Deliv Rev 2005; 57:919-28.

4. Nunes FD, Lopez LN, Lin HW, Davies C, Azevedo RB, Gow A, Kachar B. Distinct subdomain organization and molecular composition of a tight junction with adherens junction features. J Cell Sci 2006; 119:481927

5. Ebrahim S, Fujita T, Millis BA, Kozin E, Ma X, Kawamoto S, Baird MA, Davidson M, Yonemura S, Hisa Y, Conti MA, Adelstein RS, Sakaguchi H et al. NMII Forms a Contractile Transcellular Sarcomeric Network to Regulate Apical Cell Junctions and Tissue Geometry. Curr Biol 2013; 23:731-6;

6. Furuse M, Sasaki H, Fujimoto K, Tsukita S. A single gene product, claudin-1 or -2 , reconstitutes tight junction strands and recruits occludin in fibroblasts. J Cell Biol 1998; 143:391-401.

7. Inai T, Sengoku A, Hirose E, Iida H, Shibata Y. Claudin-7 expressed on lateral membrane of rat epididymal epithelium does not form aberrant tight junction strands. Anat Rec (Hoboken) 2007; 290:1431-8.

8. Van Itallie CM, Anderson JM. Claudin interactions in and out of the tight junction. Tissue Barri ers. 2013; 1: e25247.

9. Tokés AM, Kulka J, Paku S, Szik A, Páska C, Novák PK, Szilák L, Kiss A, Bögi K, Schaff Z. Claudin-1, -3 and -4 proteins and mRNA expression in benign and malignant breast lesions: a research study. Breast Cancer Res 2005; 7:R296-305.

10. Morohashi S, Kusumi T, Sato F, Odagiri H, Chiba H, Yoshihara S, Hakamada K, Sasaki M, Kijima H. Decreased expression of claudin-1 correlates with recurrence status in breast cancer. Int J Mol Med 2007; 20:139-43.

11. Higashi Y, Suzuki S, Sakaguchi T, Nakamura T, Baba S, Reinecker HC, Nakamura S, Konno H. Loss of claudin-1 expression correlates with malignancy of hepatocellular carcinoma. J Surg Res 2007; 139:68-76.

12. Lanigan F, McKiernan E, Brennan DJ, Hegarty S, Millikan RC, McBryan J, Jirstrom K, Landberg G, Martin F, Duffy MJ, Gallagher WM. Increased claudin-4 expression is associated with poor prognosis and high tumour grade in breast cancer. Int J Cancer 2009; 124:2088-97.

13. Sheehan GM, Kallakury BV, Sheehan CE, Fisher HA, Kaufman RP Jr, Ross JS. Loss of claudins-1 and -7 and expression of claudins-3 and-4 correlate with prognostic variables in prostatic adenocarcinomas. Hum Pathol 2007; 38:564-9.

14. Resnick MB, Konkin T, Routhier J, Sabo E, Pricolo VE. Claudin-1 is a strong prognostic indicator in stage II colonic cancer: a tissue microarray study. Mod Pathol 2005; 18:511-8.

15. Dhawan P, Singh AB, Deane NG, No Y, Shiou SR, Schmidt C, Neff J, Washington MK, Beauchamp RD. Claudin-1 regulates cellular transformation and metastatic behavior in colon cancer. J Clin Invest 2005; 115:1765-76.

16. Shiozaki A, Shimizu H, Ichikawa D, Konishi H, Komatsu S, Kubota T, Fujiwara H, Okamoto K, Iitaka D, Nakashima S, Nako Y, Liu M, Otsuji E. Claudin 1 mediates tumor necrosis factor alpha-induced cell migration in human gastric cancer cells. World J Gastroenterol 2014; 20:17863-76. 
17. Shiozaki A, Bai XH, Shen-Tu G, Moodley S, Takeshita H, Fung SY, Wang Y, Keshavjee S, Liu M. Claudin 1 mediates $\mathrm{TNF} \alpha$-induced gene expression and cell migration in human lung carcinoma cells. Plos One 2012; 7:e38049.

18. Liu Y, Wang L, Lin XY, Wang J, Yu JH, Miao Y, Wang EH. Anti-apoptotic effect of claudin-1 on TNF- $\alpha$-induced apoptosis in human breast cancer MCF-7 cells. Tumour Biol2012; 33:2307-15.

19. Lee JW, Hsiao WT, Chen HY, Hsu LP, Chen PR, Lin MD, Chiu SJ, Shih WL, Hsu YC. Upregulated claudin-1 expression confers resistance to cell death of nasopharyngeal carcinoma cells. Int J Cancer 2010; 126:1353-66.

20. Melchers LJ, Bruine de Bruin L, Schnell U, SlagterMenkema L, Mastik MF, de Bock GH, van Dijk BA, Giepmans BN, van der Laan BF, van der Wal JE, Roodenburg JL, Schuuring E. Lack of claudin-7 is a strong predictor of regional recurrence in oral and oropharyngeal squamous cell carcinoma. Oral Oncol 2013; 49:998-1005.

21. Dahiya N, Becker KG, Rd WW, Zhang Y Morin PJ. Claudin-7 is frequently overexpressed in ovarian cancer and promotes invasion. Plos One 2011; 6:395-402.

22. Zavala-Zendejas VE, Torres-Martinez AC, Salas-Morales B, Fortoul TI, Montaño LF, Rendon-Huerta EP.Claudin-6, 7 , or 9 overexpression in the human gastric adenocarcinoma cell line AGS increases its invasiveness, migration, and proliferation rate. Cancer Invest 2011; 29:1-11.

23. Kuhn S, Koch M, Nübel T, Ladwein M, Antolovic D, Klingbeil P, Hildebrand D, Moldenhauer G, Langbein L, Franke WW, Weitz J, Zöller M. A complex of EpCAM, claudin-7, CD44 variant isoforms, and tetraspanins promotes colorectal cancer progression. Mol Cancer Res2007; 553-67.

24. Hsueh C, Chang YS, Tseng NM, Liao CT, Hsueh S, Chang $\mathrm{JH}, \mathrm{Wu}$ IC, Chang KP. Expression pattern and prognostic significance of CLDNs 1 , 4, and 7 in nasopharyngeal carcinoma. Hum Pathol 2010; 41:944-50.

25. Suren D, Yildirim M, Kaya V, Elal R, Selcuk OT, Osma U, Yildiz M, Gunduz S, Sezer C. Expression patterns of CLDNs 1, 4, and 7 and their prognostic significance in nasopharyngeal carcinoma. J BUON 2015, 20:212-217.

26. Heiler S, Wei M, Zöller M, Thuma F. The importance of claudin-7 palmitoylation on membrane subdomain localization and metastasis-promoting activities. Cell Commun Signal 2015; 13:29.

27. Thuma F, Heiler S, Schnölzer M, Z Margot. Palmitoylated claudin7 captured in glycolipid-enriched membrane microdomains promotes metastasis via associated transmembrane and cytosolic molecules. Oncotarget. 2016; 7:30659-77. doi: 10.18632/oncotarget.8928.

28. Yeh SH, Liu RS, Wu LC, Yang DJ, Yen SH, Chang CW, Yu TW, Chou KL, Chen KY. Fluorine-18 fluoromisonidazole tumour to muscle retention ratio for the detection of hypoxia in nasopharyngeal carcinoma. Eur J Nucl Med 1996; 23: 1378-83.

29. Sui J, Wu J, Li X, Ma J, Cao X, Gao W, Ren Y. The expression and significance of hypoxia inducible factor1alpha and microvessel density in human nasopharyngeal carcinoma. Lin Chung Er Bi Yan Hou Tou Jing Wai Ke Zha Zhi 2008; 22: 269-72.

30. Yi Zhao, Tian-yun Pang, Yan Wang, Sen Wang, Hai-xian Kang, Wei-bin Ding, Wei-wei Yong, Yan-hong Bie, Xiaoguang Cheng, et al. Lmp1 stimulates the transcription of eif4e to promote the proliferation, migration and invasion of human nasopharyngeal carcinoma. Febs Journal 2014; 281, 3004-3018.

31. Matsui Y, Nakayama Y, Okamoto M, Fukumoto Y, Yamaguchi N. Enrichment of cell populations in metaphase, anaphase, and telophase by synchronization using nocodazole and blebbistatin: a novel method suitable for examining dynamic changes in proteins during mitotic progression.[J]. European Journal of Cell Biology 2012; 91:413-9.

32. Itallie $\mathrm{C} \mathrm{M} \mathrm{V}$, Anderson $\mathrm{J} \mathrm{M}$. Claudin interactions in and out of the tight junction [J]. Tissue Barriers 2013, 1:e25247-e25247.

33. Dewhirst MW. Intermittent hypoxia furthers the rationale for hypoxia-inducible factor-1 targeting. Cancer Res 2007; 67:854-5.

34. Martinive P, Defresne F, Bouzin C, Saliez J, Lair F, Grégoire V, Michiels C, Dessy C, Feron O. Preconditioning of the tumor vasculature and tumor cells by intermittent hypoxia: implications for anticancer therapies. Cancer Res 2006; 66:11736-44.

35. Mani SA, Guo W, Liao MJ, Eaton EN, Ayyanan A, Zhou AY, Brooks M, Reinhard F, Zhang CC, Shipitsin M, Campbell LL, Polyak K, Brisken C, et al. The epithelialmesenchymal transition generates cells with properties of stem cells. Cell 2008; 133:704-15.

36. Leotlela PD, Wade MS, Duray PH, Rhode MJ, Brown HF, Rosenthal DT, Dissanayake SK, Earley R, Indig FE, Nickoloff BJ, Taub DD, Kallioniemi OP, Meltzer P, et al. Claudin-1 overexpression in melanoma is regulated by PKC and contributes to melanoma cell motility. Oncogene 2007; 26: 3846-56.

37. Aga M, Bentz GL, Raffa S, Torrisi MR, Kondo S, Wakisaka N, Yoshizaki T, Pagano JS, Shackelford J. Exosomal HIF1 $\alpha$ supports invasive potential of nasopharyngeal carcinomaassociated LMP1-positive exosomes. Oncogene 2014; 33:4613-22.

38. Xueguan L, Xiaoshen WZ, Yong sheng Z, Chaosu H, Chunying S, Yan F. Hypoxia inducible factor-1 alpha and vascular endothelial growth factor expression are associated with a poor prognosis in patients with nasopharyngeal carcinoma receiving radiotherapy with carbogen and nicotinamide. Clin Oncol (R Coll Radiol) 2008; 20:606-12. 
39. Cheng T, Yuan Y, Shen H, Yu H Scadeen DT. P 18 in stem cell manipulations: US Patent No. US7863044B2; 2011.

40. Franklin DS, Xiong Y. Induction of p18INK4c and its predominant association with CDK4 and CDK6 during myogenic differentiation. Mol Biol Cell, 1996; 7:1587-99.

41. Kimura H, Braun RD, Ong ET, Hsu R, Secomb TW, Papahadjopoulos D, Hong K, Dewhirst MW. Fluctuations in red cell flux in tumor microvessels can lead to transient hypoxia and reoxygenation in tumor parenchyma. Cancer Res 1996; 56:5522-8.

42. Yasui H, Matsumoto S, Devasahayam N, Munasinghe JP, Choudhuri R, Saito K, Subramanian S, Mitchell JB, Krishna MC. Low-field magnetic resonance imaging to visualize chronic and cycling hypoxia in tumor-bearing mice. Cancer Res 2010; 70:6427-36.
43. Moeller BJ, Cao YC, Dewhirst MW. Radiation activates HIF-1 to regulate vascular radiosensitivity in tumors: role of reoxygenation, free radicals, and stress granules. Cancer Cell 2004; 5:429-41.

44. Mathieu J, Zhou W, Xing Y, Sperber H, Ferreccio A, Agoston Z, Kuppusamy KT, Moon RT, Ruohola-Baker H. Hypoxia-inducible factors have distinct and stage-specific roles during reprogramming of human cells to pluripotency. Cell Stem Cell 2014; 14:592-605.

45. Kuo K T, Chen C L, Chou T Y, T-Y Chou, Yeh C T, Lee W H Lee, Wang L S. Nm23H1 mediates tumor invasion in esophageal squamous cell carcinoma by regulation of CLDN1 through the AKT signaling. Oncogenesis, 2016, 5. 